\title{
Comunicación

\section{La asignatura ciudadana en las cuatro grandes reformas del libro de texto gratuito en México}

CRISTINA GALLO ESTRADA ${ }^{1}$

Sarah Corona Berkin, profesorainvestigadora del Departamento de Estudios de la Comunicación Social de la Universidad de Guadalajara, es doctora en Comunicación por la Universidad Católica de Lovaina, Bélgica. Tiene una larga trayectoria en el estudio de la comunicación y educación interculturales, así como en el estudio de la imagen. Corona ha analizado además contenidos en imágenes y texto en libros de texto gratuitos (LTG).

En La Asignatura Ciudadana en las Cuatro Grandes Reformas del LTG en México (1959-2010),
Corona Berkin, S. (2015). La asignatura ciudadana en las cuatro grandes reformas del LTG en México (1959-2010). México: Siglo XXI Editores, $101 \mathrm{pp}$.

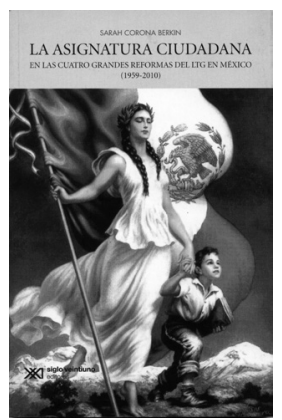

libro que parte de un proyecto más amplio sobre el uso del recurso visual en las políticas educativas de la Secretaría de Educación Pública (SEP), Corona analiza los LTG de la Secretaría desde sus primeras ediciones en 1959, seguidas por las reformas de 1971, 1992 y 2000, desarrolladas cada una en un capítulo. Identifica las continuidades y

1 Universidad de Guadalajara, México.

Correo electrónico: cristina.ge89@gmail.com 
transformaciones entre cada nueva edición publicada, así como las posiciones políticas e ideológicas que se presentan en sus contenidos. Para esta observación, la autora se basa en los conceptos de ciudadano que se manejan en los textos, así como las estrategias comunicativas orientadas a que los alumnos se conviertan en ciudadanos; es decir, qué es un ciudadano y cómo es el ejercicio de la ciudadanía.

La primera parte de La Asignatura Ciudadana en las Cuatro Grandes Reformas del LTG en México (1959-2010), nos introduce a los temas abordados a lo largo del libro, explica las decisiones metodológicas y se enfoca en temas recurrentes para dar respuesta a sus preguntas: el mestizaje, el indígena y la diversidad; el nacionalismo, y la laicidad (p. 10). Cada capítulo subsecuente inicia con una descripción del panorama social, político y cultural del periodo en cuestión, y presenta a los actores involucrados con las políticas educativas y la toma de decisiones en cuestión de materiales educativos.

El primer capítulo "Los libros de la patria", aborda el surgimiento de los LTG como una iniciativa nacional histórica para uniformar los contenidos y hacer llegar los mismos materiales educativos a todos los niños del país, acompañada de una importante inversión en materia de educación. En este periodo entra en vigor el Plan de Once Años, "el mayor proyecto en la historia nacional de edición de libros escolares. Por primera vez, los libros de texto serían universales, gratuitos y obligatorios" (p. 21).

La autora identifica que las líneas rectoras en estos primeros libros fueron el nacionalismo, una imagen legalista de ciudadanía y la exigencia de valores éticos más que políticos. Así mismo, la ciudadanía se ve como una formalidad que se obtiene solo por tener la edad necesaria, y el valor ciudadano por excelencia es la honradez.

En opinión de la autora, las imágenes privilegian la figura de los héroes patrios y las herramientas comunicativas para representar al ciudadano promueven un punto de vista universal, y no buscan incentivar a una participación activa, sino más bien contemplativa, dejando al Estado el papel de actor principal. Los ciudadanos solo presentan diferencias entre sí respecto de su lugar de vivienda (campo o ciudad).

El segundo capítulo "Los libros de la primera reforma" aborda el periodo de 1971 a 1992, en el que abunda un discurso oficial crítico del 
imperialismo y el capitalismo. En este periodo se realiza una consulta a maestros con el fin de tomar en cuenta sus opiniones para mejorar el plan de estudios, las metodologías y los contenidos.

Los libros derivados de esta reforma, escritos por intelectuales y especialistas de instituciones prestigiosas obtuvieron críticas por parte de algunos sectores de la población, por ejemplo: que ofrecían una lectura difícil, que no fueron probados frente a alumnos, o que presentaban demasiado material.

Los ciudadanos de esta reforma están unidos por lazos de hermandad con países de Latinoamérica -justificado por la acogida de refugiados políticos de dictaduras latinoamericanas-y se privilegia la solidaridad como valor cívico. En estos libros se critica el desarrollo desequilibrado de los últimos años y se abstienen de prometer seguridad, a diferencia de los materiales anteriores. Corona identifica una postura menos optimista y la idea de que ahora "la educación por sí sola no garantiza movilidad social" (p. 44).

En cuanto a las imágenes, los símbolos internacionales ocupan un espacio importante y la representación del ciudadano es más bien folklórica, y toman lugar la tecnología y los héroes nacionales; mientras que las herramientas -es decir, los ejemplos y ejercicios que se utilizan para explicar cómo se es un buen ciudadano- se enfocan en "aprender a pensar, imaginar e inventar" (p. 47).

La autora observa que los libros de este periodo son los que han tomado una postura política más fuerte y explícita, difieren de los anteriores al aceptar que el país se encuentra en un periodo de rápidas transformaciones y reflexiona:

Los cambios realizados esporádicamente a los libros de texto gratuitos durante estos años, sin embargo, no responden a una dirección clara y meditada. Reflejan, es cierto, las nuevas posturas políticas e ideológicas de las nuevas épocas, pero carecen de planeación y claridad (p. 58).

El capítulo "La reforma de los LTG de 1992-2000” estudia los cambios en materia educativa en un periodo de transformaciones económicas y sociales, donde el país se está redireccionando y "modernizando". Los libros de este periodo se derivan del Programa para la Moderniza- 
ción Educativa, pero aparecen nuevas ediciones de algunos libros a lo largo de todo el periodo.

En esta época de crisis económica se buscaba la unidad nacional, el apego a la ley y se privilegió la capacitación técnica de cara al futuro. El reto de estos libros era principalmente "conciliar un nacionalismo que diera unidad al país, con una modernización que exigía ciertas renuncias al modelo de nacionalismo tradicional" (p. 67).

Las imágenes de esta reforma presentan una población mexicana homogénea y una visión limitada de género unida alrededor de los símbolos patrios; mientras, las herramientas están enfocadas en la lectura y el manejo de la información. Corona hace notar que las lecciones no buscan la enseñanza de habilidades de juicio crítico o la aplicación de los conocimientos, sino que tienen una visión tecnocrática: "hacer haciendo" (p. 76).

El último capítulo, "Los libros del cambio" concierne al periodo 2000-2012. Hasta este momento histórico, el mandato del Partido Revolucionario Institucional (PRI) dotaba a cada nueva edición de cierta unidad ideológica y política, lo cual se rompe con la alternancia del poder gracias a la llegada del Partido Acción Nacional (PAN), que gana una elección presidencial por primera vez en siete décadas.

El contexto social y económico de este periodo se caracteriza por un crecimiento exponencial del acceso a Internet, una importante presencia de la televisión de paga en los hogares, así como el consumo de programas televisivos estadounidenses.

En este sexenio se crea el "Programa Nacional de Educación 20012006", que pretende enfrentar como principales retos la desigualdad de oportunidades educativas, mejorar la calidad de los aprendizajes, y tender las bases de poder y toma de decisiones.

Los ciudadanos mexicanos que se representan en estos libros son principalmente blancos, criollos, urbanos; mientras que los campesinos, obreros y mestizos no aparecen. No hay grandes rastros de diversidad, los niños que aparecen en las ilustraciones presentan rasgos más bien homogéneos, y el ciudadano representado es "más ambiguo que mestizo" (p. 89), como observa la autora: "estos nuevos libros consideran que las diferencias producen un riesgo de desadaptación social" (p. 83). 
En estos libros los héroes no son los protagonistas y el único referente de unidad nacional es la ley, no hay una identidad ciudadana como tal y se habla de los derechos como algo privado: "Todo se reduce a la moral privada, la tolerancia individual, buenas intenciones y obediencia" (p. 89).

Las lecciones no ofrecen herramientas para ser un buen ciudadano y actuar democráticamente: se propone "platicar" (p. 89) sobre las decisiones de cada uno, pero, si bien se menciona el diálogo como herramienta democrática, los LTG no explicitan las formas de lograrlo.

Al final del libro la autora propone seis estrategias para las futuras reformas de contenidos de los LTG:

1. Apropiación de la lengua: aprender a leer y escribir como herramienta para dialogar de forma equitativa, además de promover en todos los niveles una lengua indígena y el inglés.

2. Dignificación de los maestros/dignificación de todos: reconocer que los maestros son el sector central de la educación y que sin ellos "los LTG no tienen sentido de ser" (p. 93).

3. Tecnologías para pensar: decir no a la información inmediata y a las tecnologías que actúan en menoscabo del pensamiento.

4. El mestizaje productivo: escuchar a los diferentes sectores desde su propia voz, reconocer la diversidad social y cultural de México. Promover el diálogo entre distintos como herramienta para resolver problemas.

5. La transversalidad en la educación ciudadana: repensar qué aportan las materias para ser buenos ciudadanos. "La educación ciudadana debe sustentarse en lo que el niño puede hacer y no en la simulación de lo que no puede" (p. 95).

6. La imagen en la educación: adoptar una política de la imagen y que ésta coincida con los ciudadanos mexicanos de hoy.

Escrito de forma clara y con un lenguaje sencillo, el presente libro resulta apto tanto para académicos como para el público que quiera conocer más sobre el desarrollo de los libros de texto gratuitos a lo largo de la historia. De igual forma, los datos históricos y estadísticos que se incluyen resultan muy relevantes para el estudio de materiales 
educativos y de la implementación de políticas públicas en diversos contextos de México.

Sin duda, La Asignatura Ciudadana en las Cuatro Grandes Reformas del LTG en México (1959-2010) es una herramienta útil y pertinente en un contexto histórico y social donde desde el gobierno se exalta una reforma educativa que muchos no identifican como tal, y se ataca más que nunca a la figura de los maestros, un momento convulso en el que es particularmente relevante entender el camino que ha recorrido la política educativa en el país; el papel que han desempeñado sus docentes y autoridades, así como los resultados alcanzados en un esfuerzo por dar la misma educación a todos los niños del país. 